\title{
Fixed drug eruption to cetirizine with positive lesional patch tests to the three piperazine derivatives
}

\author{
Mariana Cravo, MD, Margarida Gonçalo, MD, and Américo Figueiredo, MD, PhD
}

From the Clinic of Dermatology, University Hospital, Coimbra, Portugal

\author{
Correspondence \\ Mariana Cravo, MD \\ Serviço de Dermatologia \\ Hospitais da Universidade de Coimbra \\ Praceta Mota Pinto \\ 3000-075 Coimbra \\ Portugal \\ E-mail:mariana.cravo@netcabo.pt
}

\begin{abstract}
Background The $\mathrm{H} 1$-antihistamine cetirizine, a piperazine derivative widely used in daily practice, is rarely the cause of cutaneous drug reaction. Nevertheless, four cases of fixed drug eruption (FDE) as a result of this drug have been described recently. We present the case of a 45-year-old woman with a multilocalized FDE following oral intake of cetirizine for allergic rhinitis.

Methods Patch testing with hydroxyzine $1 \%$ and $10 \%$ in petrolatum (Chemotechnique), and with powdered Zyrtec $®$ (cetirizine) and Xyzal $₫$ (levocetirizine) pills, prepared at $20 \%$ in water and at $20 \%$ in petrolatum, was performed in both residual lesions and healthy skin.

Results Positive results (++) to these drugs ( $24 \mathrm{~h}$ occlusion and readings at days 2 and 3 ) were obtained in residual lesions only. These results allowed us to confirm the drug responsible for this FDE and to study cross-reactions between antihistamines of the same chemical family. Conclusions To the best of our knowledge, this is the first report of FDE to cetirizine with positive patch testing to hydroxyzine, cetirizine, and levocetirizine. This case highlights the importance of patch testing in the study of cutaneous drug reactions, namely FDE.
\end{abstract}

\section{Introduction}

HI-antihistamine drugs, widely used in the treatment of allergic diseases, have an excellent safety profile, particularly those of the second and third generations. Cutaneous sideeffects, such as fixed drug eruption (FDE), are very uncommon, and only a few cases have been described. Patch testing is not regularly performed, because re-challenge with the reappearance of skin lesions identifies the offending drug and the reactivity of patch tests in FDE is variable. ${ }^{\mathrm{I}}$

\section{Case Report}

A 45-year-old woman presented in May 2005 with multiple, round, erythematoviolaceous, well-defined plaques, with central blisters, localized on the trunk, forearms, and dorsum of the hands. She recounted three previous cutaneous eruptions with the same morphologic features in the same sites that had disappeared spontaneously in 8-10 days leaving only residual brown to gray hyperpigmentation, a condition with clinical and evolutionary features typical of FDE. In the last episode, the patient described the oral intake of Io mg cetirizine $\left(\right.$ Zyrtec $\left.{ }^{\circledR}\right)$ for allergic rhinitis $4 \mathrm{~h}$ before lesional reactivation, but she did not recall any particular drug intake before the other episodes. Because of the exuberance of the lesions, the patient was treated with methylprednisolone, $32 \mathrm{mg} / \mathrm{day}$, with rapid tapering in 8 days.
To confirm the etiology of this FDE, 6 weeks later, when there were only residual hyperpigmented lesions, patch tests were performed, according to the guidelines for performing skin testing in drug eruptions. ${ }^{2}$ Powdered Zyrtec $®$, prepared at $20 \%$ in water and petrolatum, and hydroxyzine at $10 \%$ in petrolatum (Chemotechnique) were patch tested using Finn Chambers on Scanpor tape on both healthy skin of the back and residual lesions ( $24 \mathrm{~h}$ occlusion and readings at days 2 and 3 ). Positive results (++) were obtained for Zyrtec® powder and hydroxyzine on residual lesions only (Fig. I). One month later, hydroxyzine at $\mathrm{I} \%$ in petrolatum (Chemotechnique) and powdered Xyzal® (levocetirizine), prepared at $20 \%$ in water and petrolatum, induced positive reactions $(++)$ on residual lesions only at 24 and $48 \mathrm{~h}$ (Fig. 2). Other suspicious drugs tested on lesional skin (nimesulide and piroxicam in $\mathrm{I} \%$ petrolatum) gave negative results. No reaction was observed with the 30 allergens of the Portuguese Contact Dermatitis Group Standard Series tested on normal back skin. No relapse was observed when the patient avoided the three reactive drugs: hydroxyzine, cetirizine, and levocetirizine. No oral provocation tests were performed.

\section{Discussion}

More than roo drugs have been implicated in FDE; however, this side-effect is more commonly found with tetracyclines, sulfonamides, sulfone, penicillins, pyrazolones, barbiturates, 


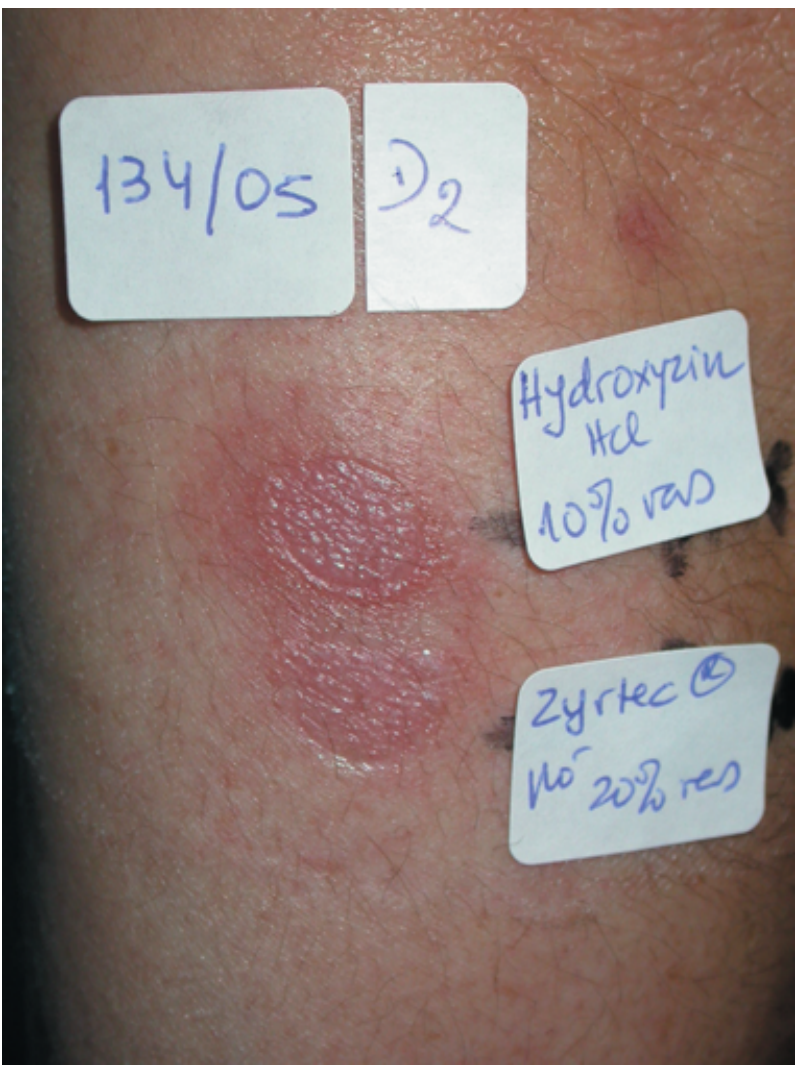

Figure 1 Positive patch tests with hydroxyzine (10\% in petrolatum) and Zyrtec ${ }^{\circledR}$ (cetirizine) powder $(20 \%$ in petrolatum) at $48 \mathrm{~h}$ in a residual lesion

phenolphthalein, aspirin, and oral contraceptives. ${ }^{3-5}$ In our experience, FDE is mainly caused by the nonsteroidal antiinflammatory drugs (NSAIDs) piroxicam and nimesulide., ${ }^{2,6-8}$ It has also been described as a side-effect of some anti-HIantihistamine drugs, such as cyclizine lactate, diphenhydramine hydrochloride, phenothiazines, hydroxyzine, ${ }^{3}$ and loratadine. ${ }^{4,9}$ Four cases of FDE to cetirizine have been described, two to cetirizine only, ${ }^{\mathrm{IO}, \mathrm{II}}$ one to cetirizine and hydroxyzine, ${ }^{\mathrm{I}}$ and one to cetirizine and levocetirizine. ${ }^{3}$

The pathogenesis of FDE is not completely understood, but epidermal CD8 T cells retained in lesional skin are believed to contribute to immunologic "memory," being reactivated on re-challenge. ${ }^{\mathrm{I}, 5, \mathrm{I} 2}$

Oral challenge can be used to confirm the etiology of FDE; 5 however, there are risks involved in this approach, namely anaphylactic reactions ${ }^{\mathrm{I}}$ or intense lesional reactivation with a significant increase in the number of lesions.

Patch testing at the site of a previous lesion yields a positive response in up to $43 \%$ of cases. ${ }^{13}$ Reactivity depends on the drug and the vehicle, is usually seen before $24 \mathrm{~h}$, and is observed exclusively on lesional skin. Retained memory-

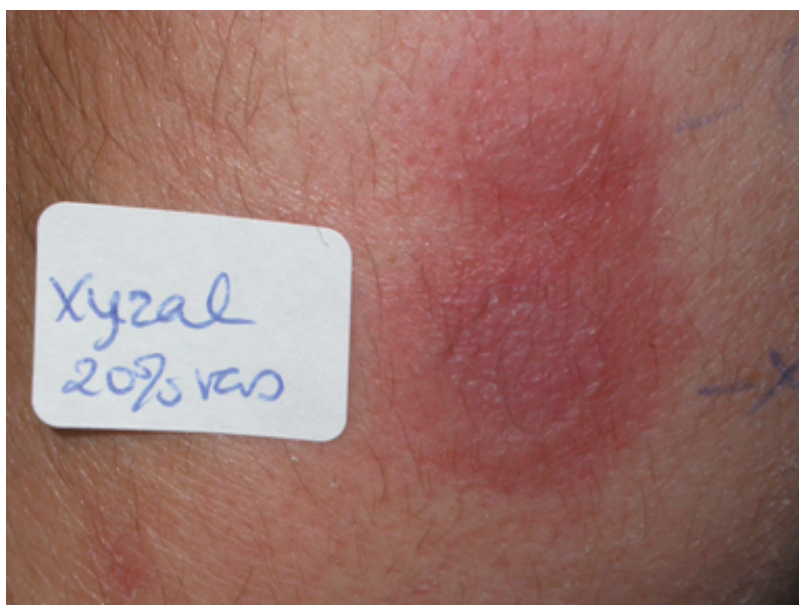

Figure 2 Positive patch test with Xyzal ${ }^{\circledR}$ (levocetirizine) powder $(20 \%$ in petrolatum $)$ at $24 \mathrm{~h}$ in a residual lesion

specific $\mathrm{T}$ lymphocytes may play a key role in evoking the patch test reaction on lesional skin only. ${ }^{\circ}$ Patch testing is safer than oral provocation tests, allows the study of several drugs at the same time, and can also be interesting in the study of cross-reactions between drugs, as in previously reported cases. ${ }^{6,7}$

Cutaneous reactivity to the three $\mathrm{HI}_{\text {-antihistamines is }}$ caused by the fact that they have the same chemical piperazine structure and similar pharmacologic profiles. ${ }^{3}$ In vivo, $45 \%$ of hydroxyzine is transformed into cetirizine and levocetirizine is the active $(R)$-enantiomer of cetirizine. ${ }^{3}$ To the best of our knowledge, this is the first report of FDE to cetirizine with positive patch tests to hydroxyzine, cetirizine, and levocetirizine.

\section{References}

I Assouere MN, Mazereeuw-Hautier J, Bonafe JL. Cutaneous drug eruption with two antihistaminic drugs of the same chemical family: cetirizine and hydroxyzine. Ann Dermatol Venereol 2002; I29: I 295-I 298.

2 Barbaud A, Gonçalo M, Bruynzeel D, et al. Guidelines for performing skin tests with drugs in the investigation of cutaneous adverse drug reactions. Contact Dermatitis 200I; 45: $32 \mathrm{I}-328$.

3 Mahajan VK, Sharma NL, Sharma VC. Fixed drug eruption: a novel side-effect of levocetirizine. Int J Dermatol $2005 ; 44$ : 796-798.

4 Pionetti CH, Kien MC, Alonso A. Fixed drug eruption due to loratadine. Allergol Immunopathol (Madr) 2003; 3I: 29I293.

5 Kauppinen K, Stubb S. Fixed eruptions: causative drugs and challenge tests. Br J Dermatol I985; I I 2: 575-578.

6 Oliveira HS, Gonçalo M, Reis JP, et al. Fixed drug eruption to piroxicam. Positive patch tests with cross-sensivity to tenoxicam. J Dermatol Treat I999; I0: 209-2 I 2.

7 Gonçalo M, Oliveira HS, Fernandes B, et al. 
Topical provocation in fixed drug eruption from nonsteroidal anti-inflammatory drugs. Exogenous Dermatol 2002; I: 8I-86.

8 Robalo Cordeiro M, Gonçalo M, Fernandes B, et al. Positive lesional patch tests in fixed drug eruptions from nimesulide. Contact Dermatitis 2000; 43: 307.

9 Ruiz-Genao DP, Hernandez-Nunez A, Sanchez J, et al. Fixed drug eruption due to loratadine. Br J Dermatol 2002; I46: 528-529.

Io Kranke B, Kern T. Multilocalized fixed drug eruption to the antihistamine cetirizine. J Allergy Clin Immunol 2000; I06: 988.

I I Inamadar AC, Palit A, Athanikar SB, et al. Multiple fixed drug eruptions due to cetirizine. Br J Dermatol 2002; I46: 528-529.

I2 Crowson A, Magro C. Recent advances in the pathology of cutaneous drug eruptions. Dermatol Clin I999; I7: 537.

I3 Barbaud A, Reichert-Penetrat S, Trechot P, et al. The use of skin testing in the investigation of cutaneous adverse drug reactions. Br J Dermatol I998; I39: 49-58. 